Antonio Carlos Frizzo

\author{
A Trilogia Social: estrangeiro, \\ órfão e viúva no Deuteronômio \\ e sua recepção na Mishná
}

Tese de Doutorado

DEPARTAMENTO DE TEOLOGIA

Programa de pós-graduação em Teologia 


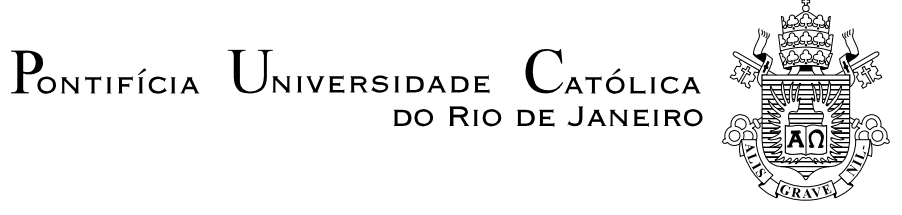

Antonio Carlos Frizzo

\section{A Trilogia Social: estrangeiro, órfão e viúva no Deuteronômio e sua recepção na Mishná}

\section{Tese de Doutorado}

Tese apresentada ao Programa de Pósgraduação em Teologia da PUC-Rio como requisito parcial para obtenção do título de Doutor em Teologia.

Orientadora: Maria de Lourdes Corrêa Lima 


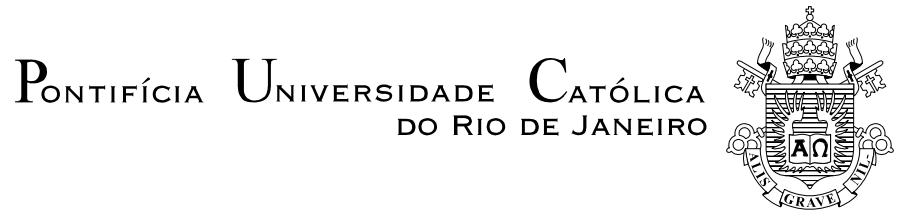

\section{Antonio Carlos Frizzo}

\section{A Trilogia Social: estrangeiro, órfão e viúva no Deuteronômio e sua recepção na Mishná}

Tese apresentada como requisito parcial para obtenção do grau de Doutor pelo Programa de PósGraduação em Teologia do Departamento de Teologia do Centro de Teologia e Ciências Humanas da PUC-Rio. Aprovada pela Comissão Examinadora abaixo assinada.

Prof $^{\mathrm{a}}$ Maria de Lourdes Corrêa Lima
Orientadora
Departamento de Teologia - PUC-Rio

Prof. Isidoro Mazzarolo Departamento de Teologia - PUC-Rio

Prof. Ludovico Garmus Departamento de Teologia - PUC-Rio

Prof. Vicente Artuso

PUC-PR

Prof. Paulo Severino da Silva Filho Seminário Teológico Presbiteriano Simonton

Prof. Paulo Fernando Carneiro da Andrade Coordenador Setorial de Pós-Graduação e Pesquisa do Centro de Teologia e Ciências Humanas - PUC-Rio 
Todos os direitos reservados. É proibida a reprodução total ou parcial do trabalho sem autorização da universidade, do autor e da orientadora.

\section{Antonio Carlos Frizzo}

Graduou-se em Teologia na Faculdade Nossa Senhora da Assunção de São Paulo em 1984. Defendeu a tese de mestrado em 1999, pelo Instituto Católico de Paris, resultado dos estudos sobre a relação entre judaísmo e cristianismo, no Instituto Pontifício Ratisbonne de Jerusalém. Leciona teologia bíblica (Antigo e Novo Testamento), é responsável pelo curso de línguas bíblicas (hebraico e grego) na Faculdade Dehoniana, Taubaté e no ITEFIST (Instituto de Teologia e Filosofia Santa Terezinha), São José dos Campos, São Paulo. É padre na diocese de Guarulhos, São Paulo.

Ficha Catalográfica

Frizzo, Antonio Carlos

A trilogia social : estrangeiro, órfão e viúva no Deuteronômio e sua recepção na Mishná / Antonio Carlos Frizzo; orientadora: Maria de Lourdes Corrêa Lima. - 2009.

235 f.; $30 \mathrm{~cm}$

Tese (Doutorado em Teologia)-Pontifícia Universidade Católica do Rio de Janeiro, Rio de Janeiro, 2009.

Inclui bibliografia

1. Teologia - Teses. 2. Trilogia social. 3. Estrangeiro. 4. Órfão. 5. Viúva. 6. Mishná. 7. Deuteronômio. 8. Defesa da vida. I. Lima, Maria de Lourdes Corrêa. II. Pontifícia Universidade Católica do Rio de Janeiro. Departamento de Teologia. III. Título.

CDD: 200 
Ao meu pai, Antonio Frizzo (in memoriam), com quem aprendi a sonhar e trabalhar por um mundo justo e solidário. À professora Ana Flora Anderson, mestra nos primeiros passos no estudo das Escrituras; Ao professor e amigo, Dr. Pe. Emanuel Bouzon (in memoriam), pela confiança e por ter acenado os primeiros passos desse trabalho. 


\section{Agradecimentos}

Ao Deus Um, pela saúde e por tantas bênçãos recebidas no dia-a-dia.

À minha mãe Isabel dos Santos Frizzo que, no silêncio e na atitude de atenta observadora, colaborou, em muito, na elaboração deste trabalho.

À Maria de Lourdes Corrêa Lima, minha orientadora, conhecedora, como poucos, da ciência bíblica, exigente e transbordante de simplicidade e amizade.

À Igreja Particular de Guarulhos, na pessoa do nosso Bispo Luiz Gonzaga Bergonzini, onde por mais de trinta anos vivo e celebro o dinamismo da fé e missão, por ter-me possibilitado tempo e apoio integral no desenvolvimento da pesquisa.

Ao meu pároco, Savério Lípori e agentes de pastoral da Igreja Santa Cruz, Jd. Presidente Dutra, pelas inúmeras vezes em que assumiram minhas tarefas cotidianas, possibilitando-me mais tempo para as pesquisas.

Ao Centro Bíblico Verbo, onde pensamos as Escrituras na vida de nossa gente. Lembro a amiga Cecília Toseli, os professores Ademar Kaefer, Shigeyuki Nakanoso, às professoras Maristela Tezza e Maria Antônia Marques. Essa última foi uma constante assessora. 
À Faculdade Dehoniana, em Taubaté e ao ITEFIST de São José dos Campos, espaços de amizade, reflexão e debate em torno das Escrituras.

À professora Deucélia Adegas Pêra, quanto tenho a agradecer! Ela, embora travando uma luta contra um câncer, sempre suplantou as dores ou desânimo e fez uma revisão impecável deste trabalho.

Ao aluno Messias Rochinski pela ajuda no acerto do software.

Ao professor Élio Passeto, do Centro de Estudos Judaico-Cristão Ratisbonne, em Jerusalém, pelos conselhos, leitura e revisão dos capítulos envolvendo a tradição judaica.

À Irmã Maria do Rosário, bibliotecária da École Biblique de Jerusalém, pelas constantes dicas bibliográficas.

Ao Prof. Ludovico Garmus, funcionárias e funcionários da Biblioteca do Instituto Teológico Franciscano, Petrópolis, RJ, pela amizade solidificada ao longo do trabalho. 


\section{Resumo}

Frizzo, Antonio Carlos; Lima, Maria de Lourdes Corrêa. A Trilogia Social: estrangeiro, órfão e viúva no Deuteronômio e sua recepção na Mishná. Rio de Janeiro, 2009. 235 p. Tese de Doutorado - Departamento de Teologia, Pontifícia Universidade Católica do Rio de Janeiro.

A presente tese aborda uma reflexão bíblico-teológica sobre a trilogia

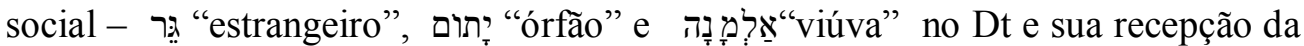
Mishná. No livro encontramos seis explícitas referências à trilogia: 10,12-22; $14,28-29 ; 16,9-12 ; 24,17-21 ; 26,12-15 ; 27,11-26$. A presença dessas categorias acena para um significativo conjunto de normas jurídicas no Antigo Israel. As leis foram praticadas para defender os direitos de grupos socialmente vulneráveis, diante de um determinado contexto político e social, como é possível verificar no embate com o projeto beligerante do império assírio (722 a.C.) e, mais tarde, com a experiência da comunidade religiosa pós-exílica (537 a.C.), após confrontos com as tropas babilônicas. As narrativas, além desse aspecto, revelam o nível de intimidade envolvendo YHWH e a comunidade religiosa, que deve engajar-se para fazer prevalecer a prática do direito e da justiça aos grupos socialmente desfavorecidos, como prova de sua interação com YHWH. Num contexto social completamente adverso às comunidades judaítas, nos dois primeiros séculos da nossa era, a Mishná baliza os esforços dos sábios fariseus ao colocarem em prática os preceitos, sempre atuais, da Torá. Ler os dois universos literários - Dt e Mishná - a partir da ótica dos grupos socialmente frágeis, é um desafio para se compreender o valor significativo que teve a tradição judaica na compreensão do conceito "Palavra de YHWH".

\section{Palavras-chave}

Trilogia social, estrangeiro, órfão, viúva, Mishná, Deuteronômio, defesa da vida. 


\section{Resumen}

Frizzo, Antonio Carlos; Lima, Maria de Lourdes Corrêa (Orientadora). Social Trilogia: El extranjero, el huérfano y la viuda en el Deuteronomio y su recepción en la Mishna. Rio de Janeiro, 2009. 235 p. Tesis Doctoral - Departamento de Teologia, Pontifícia Universidade Católica do Rio de Janeiro.

El objetivo es abordar una reflexión bíblico-teológica sobre la trilogía

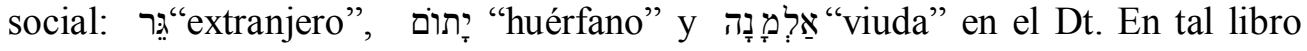
encontramos seis referencias explícitas a esta trilogía: 10,12-22; 14,28-29; 16,9$12 ; 24,17-21 ; 26,12-15 ; 27,11-26$. La presencia de estas categorías nos remite para un conjunto significativo de normas jurídicas en la antigua Israel. Las leyes se hicieron para la defensa de los derechos de los grupos socialmente vulnerables, dado a un determinado contexto sociopolítico, como se puede ver en el enfrentamiento con el proyecto beligerante del imperio Asirio (722 a.C.) y posteriormente con la experiencia de las comunidades religiosas del pos exilio (537 a.C.), y tras los enfrentamientos con las tropas Babilónicas. Tales descripciones; y más allá de estos puntos; indican el nivel de intimidad que envuelve a YHWH y a las comunidades religiosas, las cuales deben dedicarse para hacer prevalecer la práctica de la ley y la justicia en los grupos socialmente desfavorecidos, como prueba de su intimidad con YHWH. En un contexto social totalmente adverso para las comunidades judaicas en los primeros siglos de nuestra era, la Mishna es señal de los esfuerzos por parte de los sabios fariseos para poner en práctica los preceptos, siempre vigente del Torá. Leer los dos mundos literarios - del Mishna y el Dt - desde la perspectiva de los grupos socialmente vulnerables, es un reto importante para comprender el valor que tenía la tradición judaica en la comprensión del concepto de "la palabra de YHWH".

\section{Palabras claves}

Trilogía social, extranjero, huérfano, viuda, Mishna, Deuteronomio, defensa de la vida. 


\section{Résumé}

Frizzo, Antonio Carlos; Lima, Maria de Lourdes Corrêa (Orientatrice). La trilogie sociale dans livre de Deutéronome: exotique, orphelin et veuve et sa réception dans le Mishna. Rio de Janeiro, 2009. 235 p. Thèse de Doctorat - Departamento de Teologia, Pontifícia Universidade Católica do Rio de Janeiro.

La thèse traite d'une réflexion biblico-théologique sur la trilogie

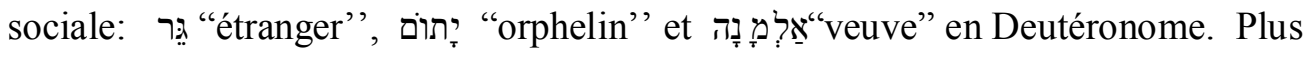
précisement dans ses chapitres 10,12-22; 14,28-29; 16,9-12; 24,17-21;26,12-15; 27,11-26. La présence de ces catégories fait appel à une importante série de règles de droits dans l'ancien Israel. Ces lois sont faites pour défendre les droits des groupes socialement vulnérables, compte tenu d'un certain contexte politique et social, comme vous pouvez le voir dans l'affrontement avec la conception des bélligerents de l'empire de syrie (722 Après Jésus Christ) et plus tard, avec l'expérience de la communauté religieuse post-Exil (537Avant Jésus Christ), après des affrontements avec les troupes Babyloniennes. Les récits, au-delà de ce point, l'intimité de Yahvé et la communauté religieuse qui doit s'enganger à la pratique du droit et de justice en faveur des groupes socialement défavorisés, comme preuve de interaction avec Yahvé. Dans un contexte social totalment néfaste pour les communautés Juives dans les deux premiers siècles de notre ère, la Mishna, phare de sages pharisiens, les efforts visant à mettre en pratique les préceptes, le cas échéant de la Torah. Lire les deux mondes littéraires - Mishna e Dt - du point de vue des groupes socialement vulnérables est um défi de comprendre la valeur qui a la tradition juive dans la compréhension de la notion du mot "Yahvé",

\section{Mots-clés}

Trilogie social, étranger, orphelin, veuve, Mishna, Deutéronome, défense de la vie. 


\section{Abstract}

Frizzo, Antonio Carlos; Lima, Maria de Lourdes Corrêa (Advisor). Social Trilogy: foreign, orphan and widow in Deuteronomy and its reception in Mishná. Rio de Janeiro, 2009. 235 p. Doctoral Thesis- Departamento de Teologia, Pontifícia Universidade Católica do Rio de Janeiro.

The aim is to discuss the biblical-theological reflection on the social

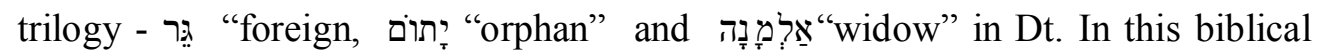
book are six explicit references to this trilogy: 10, 12-22, 14, 28-29, 16, 9-12, 24, $17-21,26,12-15,27,11-26$. The presence of these categories points out the significant set of legal rules in Ancient Israel. The laws were made in order to defend the rights of socially vulnerable groups, in a certain political and social context, as you can find out from the clash with the design of the belligerent Assyrian Empire (722 BC) and later, with the experience of religious post-exile community (537 BC), after clashes with the troops of Babylon. The narratives, beyond this point, show the level of intimacy involving YHWH. In a social context, completely adverse to the Jewish communities in the first two centuries of our area, the Mishná points out the wise Pharisees efforts to put into practice the precepts always present of the Torah. To read the two literary worlds - Dt and Mishná - from the perspective of socially vulnerable groups, is a challenge to understand the significant value that the Jewish tradition has had about the understanding of the concept "Word of YHWH".

\section{Keywords}

Social Trilogy, Foreign, Orphan, Widow, Deuteronomy, Defense of Life. 


\section{Sumário}

1. Introdução geral

2. Sinalizando os rumos da pesquisa 30

2.1. O estrangeiro, o órfão e a viúva na categoria dos pobres 34

2.1.1. ำ "estrangeiro" 35

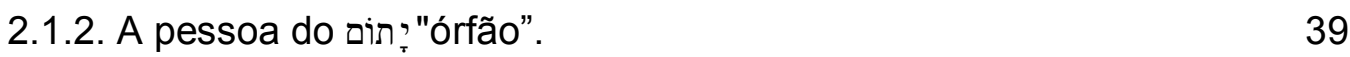

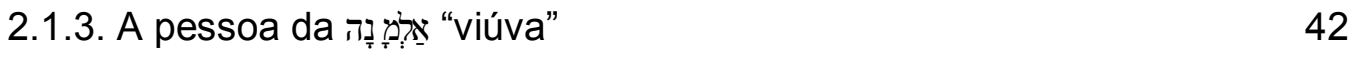

2.2. Conclusão 49

PARTE I: COMENTÁRIO DOS TEXTOS ONDE É CITADA A TRILOGIA

SOCIAL - "ESTRANGEIRO, ÓRFÃO E VIÚVA" NO DEUTERONÔMIO 51

3. Apresentação do conjunto das perícopes do Dt relacionadas com a trilogia social 52

3.1. A historicidade divina reside na realização da justiça: Dt 10,12-22 52

3.1.1. Dt 10,12-22: tradução e aspectos filológicos 53

3.1.2. Delimitação do texto, composição e estrutura 56

3.1.3. Comentário e análise semântica 62

3.2. Há um tempo determinado para a justiça: Dt 14,28-29 74

3.2.1. Dt 14,28-29: tradução, aspectos filológicos e variantes 76

3.2.2. Delimitação do texto, composição e estrutura 77

3.2.3. Comentário e análise semântica 79

3.3. Os produtos da terra utilizados na equidade social: Dt 16,9-12 87

3.3.1. Dt 16,9-12: tradução, aspectos filológicos e variantes 87

3.3.2. Delimitação, composição e estrutura 89

3.3.3. Comentário e análise semântica 92

3.4. Os pobres são lembrados durante a colheita: Dt 24,17-22 96

3.4.1. Dt 24,17-22: tradução, aspectos filológicos e variantes 97

3.4.2. Delimitação, composição e estrutura 101

3.4.3. Comentário e análise semântica 102 
3.5. A não transgressão é o meio para um mundo estável: Dt 26,12-15 107

3.5.1. Dt 26,12-15: tradução, aspectos filológicos e variantes 108

3.5.2. Delimitação, composição e estrutura 111

$\begin{array}{ll}\text { 3.5.3. Comentário e análise semântica } & 114\end{array}$

3.6. O senso cúltico contra atos que impossibilitam a realização do projeto da bênção: Dt 27,11-26 122

3.6.1. Dt 27,11-26: tradução, aspectos filológicos e variantes 122

3.6.2. Delimitação, composição e estrutura 127

3.6.3. Comentário e análise semântica 130

3.7. Conclusão: uma prática jurídica que agrada a Deus 136

PARTE II: COMENTÁRIO DOS TEXTOS DA MISHNÁ E SUA

$\begin{array}{ll}\text { INTERPRETAÇÃO DO DT } & 139\end{array}$

4. Trilogia social nos textos da Mishná 140

4.1. A importância da Mishná na formação do judaísmo 140

4.1.1. A tradição judaica em meio à experiência da הד̣iı, "desterro" 140

4.1.2. A autoridade hermenêutica de Hillel 144

4.2. 149

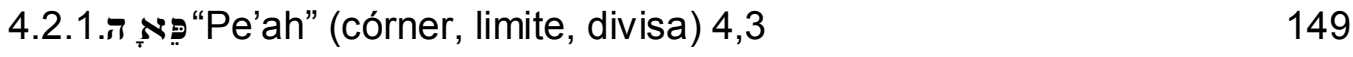

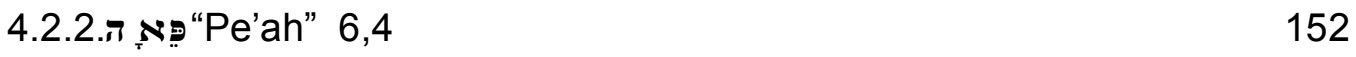

4.2.3.Pe'ah" 7,7

4.2.4. דמאי "Demay" 1,2 156

" שביעית.2.5hebiit" 7,1 159

4.2.6 מעשר שני.Maaser Sheni" 5,10 162

4.3.Seder Mo'ed" סדר מועד "Sed

4.4. מגילה "Megillah" 2,5 164

4.5. סדר נשים "Seder Nashim" 166

4.5.1. נידרים "Nedarim" 11,3 166

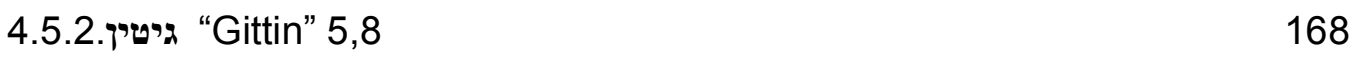

$\begin{array}{ll}\text { 4.5.3. Sotah } 9,10 & 171\end{array}$

4.6. סדר נזיקין "Seder Neziqin" 173

4.6.1.Bava Metzia" 9,13 בבא מציעה "Bara

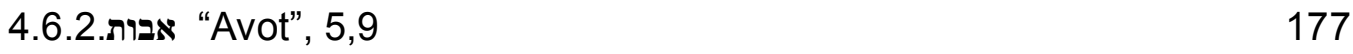


5. A trilogia social nos textos deuteronômicos e mishnáicos 183

5.1. O dever de disponibilizar os dízimos 183

5.1.1. Produtos disponibilizados no sétimo ano. 186

5.1.2. O dízimo dos pobres e a declaração no dia festivo, por excelência 189

5.1.3. O dízimo lembrado nas ocasiões festivas 191

5.1.4. A confissão do dízimo abolida pelo Sumo Sacerdote 193

5.2. O dever de garantir aos pobres o direito da respiga 197

5.2.1. O recolhimento do Pea não é ocasião de roubar o proprietário 197

5.2.2. A radicalidade da lei do "não voltar atrás" 199

5.2.3. Em qualquer situação os pobres serão lembrados 200

5.2.4. Não há meios de revogar o direito da Torá 201

5.2.5. Esforços voltados para a manutenção da paz 202

5.2.6. Relações comerciais sem usuras 204

5.3. A violação do direito dos pobres 206

$\begin{array}{ll}\text { 5.4. Conclusão } & 207\end{array}$

6. Conclusão final 208

$\begin{array}{ll}\text { 7. Referências bibliográficas } & 218\end{array}$ 


\section{Abreviaturas e siglas}

\begin{tabular}{ll} 
Ab & Abot \\
AtTeo & Atualidade Teológica \\
BA & Bible Atlas \\
BAC & Biblioteca de Autores Cristianos \\
BHS & Bíblia Hebraica Stuttgartensia \\
Bi & Biblica \\
BJ & Bíblia de Jerusalém \\
BM & Babá mẹsi'á \\
CA & Código da Aliança \\
Cadmo & Revista do Instituto Oriental de Universidade de Lisboa \\
CBSJ & Comentario Biblico San Jeronimo \\
CD & Código Deuteronômico \\
CBQ & Catholic Biblical Quarterly \\
CS & Código de Santidade \\
CSac & Código Sacerdotal \\
DBHP & Dicionário Bíblico Hebraico-Português \\
DBSup & Dictionnaire de la Bible, Suplément \\
DDD & Dictionary of Deities and Demons in the Bible \\
Dt & Dictionary of the Talmud \\
DEdJ & Dictionnaire Encyclopédique du Judaïsme \\
Dem & Děmay \\
DITAT & Dicionário Internacional de Teologia do Antigo Testamento \\
Dt & Deuteronômio \\
EB & Estudios Bíblicos \\
EsBi & Estudos Bíblicos \\
Git & Jittín \\
JBL & Journal of Biblical Literature \\
\hline Bible and Theology
\end{tabular}




$\begin{array}{ll}\text { JNES } & \text { Journal of Near Eastern Studies } \\ \text { JSOT } & \text { Journal for the Study of the Old Testament } \\ \text { LD } & \text { Lectio Divina } \\ \text { LMB } & \text { Le Monde de la Bible } \\ \text { M } & \text { Mishná } \\ \text { Meg } & \text { Měgil.lá } \\ \text { MSh } & \text { Ma'ăśer šení } \\ \text { NCBSJ } & \text { Novo Comentário Bíblico São Jerônimo } \\ \text { Ned } & \text { Nědarim } \\ \text { NRT } & \text { Nouvelle Revue Théologique } \\ \text { PT } & \text { Perspectiva Teológica } \\ \text { OBO } & \text { Orbis Biblicus et Orientalis } \\ \text { Pea } & \text { Pe’á } \\ \text { RAAO } & \text { Revue d’Assyriologie et d’Archéologie Orientale } \\ \text { RB } & \text { Revue Biblique } \\ \text { RdCT } & \text { Revista de Cultura Teológica } \\ \text { ReBi } & \text { Recherches Bibliques } \\ \text { REJ } & \text { Revue des Études Juives } \\ \text { RIBLA } & \text { Revista de Interpretação Bíblica Latino-Americana } \\ \text { Shebi } & \text { Šĕbi'it } \\ \text { Sot } & \text { Sotá } \\ \text { TBT } & \text { The Bible Today } \\ \text { TDOT } & \text { Theological Dictionary of the Old Testament } \\ \text { TM } & \text { Texto Massorético } \\ \text { WBC } & \text { Word Biblical Commentary } \\ & \end{array}$


דבר אחד יי אלהינו עלינו יי אחד על כל באי העולם,

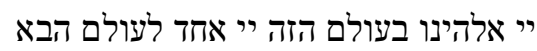

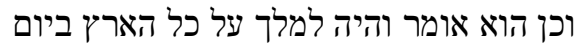

ההוא יהיה יי אחד ושמימר אוה למלך עלד.

ספרי דברים, פיסקא לא, ע״נד

Outra interpretação de Yhwh nosso Deus: sobre nós.

Yhwh é um: sobre todos os que veem ao mundo.

Yhwh nosso Deus: neste mundo. Yhwh é um: para o mundo futuro.

E assim se diz: "Yhwh se converterá em rei sobre toda a terra; e naquele dia, Yhwh será um e seu nome um".

Sifre Dt 31, 44 